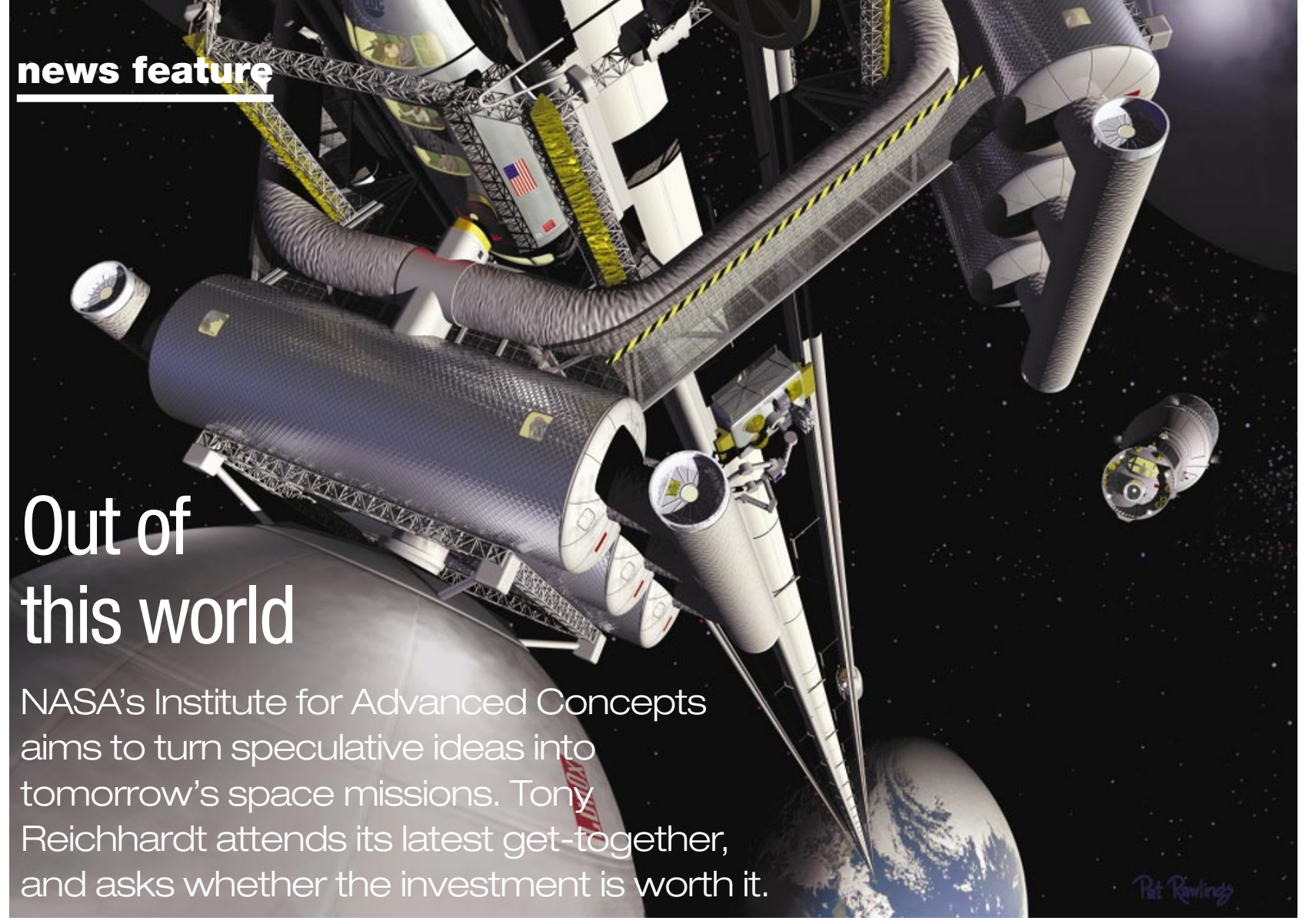

Fact or fiction? An early version of an elevator to send people into space, one unconventional idea being explored by NASA's advanced concepts institute.

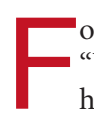

or an organization that declares itself "bounded only by the limits of the human imagination”, NASA's Institute for Advanced Concepts (NIAC) is housed in a surprisingly down-at-heel neighbourhood. Home is a nondescript, grey building in a slightly run-down section of Atlanta. Looming a mile or so in the distance are the glittering high-rise offices of the South's largest city, but this part of town is all 'space for rent' signs and cracked pavements.

Out of such surroundings, NASA hopes to nurture some big ideas. Established in 1998 with an annual budget of about \$4 million, NIAC funds researchers from outside NASA who want to work on long-term, speculative projects. "We're not looking for evolutionary ideas," says director Robert Cassanova, an aerospace engineer who used to run the nearby Georgia Tech Research Institute. "We're looking for great leaps forward.'

To date, more than 75 researchers have answered his call. Some propose technology that appears to be achievable, such as sails that use sunlight to propel spacecraft. Plans to send people and cargo into Earth orbits using space elevators are more speculative. A few ideas, such as a study of a propulsion system based on a hypothesized form of matter known as the hydrino, are deemed unworthy of study by most researchers. But all fall within NIAC's remit: the exploration of ideas that are likely to require 10-40 years to bring to fruition.

Late last month, recipients of NIAC funding gathered at a two-day workshop at the institute's headquarters to discuss their progress. "Don't let your preoccupation with reality stifle your imagination," declared one of Cassanova's slides, and first-time attendees could be heard introducing themselves with: "So what's your crazy idea?" But this was no crackpot convention, and there wasn't a warp drive in sight.

\section{The outer limits}

Cassanova says that a "good handful" of the 600-plus proposals received by NIAC to date have been science fiction. But these don't qualify for phase I funds - the institute's initial six-month grants of up to $\$ 75,000$. NIAC fellows are, for the most part, from universities, government labs and small aerospace companies. Meeting presentations resemble those at other NASA technical gatherings, with the main difference being that speculation is encouraged. Audience members may ask for clarification, but if anyone has doubts about whether an idea is practical, or even possible, they keep them to themselves.

After two days of presentations, the difficulty of running a grants programme for space missions that are decades away becomes clear. NIAC has a radical philosophy, but other institutes have far greater resources. With its limited budget, what can NIAC contribute?

Often it is a matter of finding a use for cutting-edge research from other fields. Steven Howe, a physicist formerly with the Los Alamos National Laboratory in New Mexico, has a phase I grant to develop plans for an antimatter propulsion system. Antimatter rockets, which would use the energy produced when matter and antimatter annihilate each other, have been dreamed about for decades. But Howe, who founded Hbar Technologies, a Chicago-based company that aims to develop antimatter technologies, points out that physics is now catching up with science fiction.

Last month, researchers at CERN, the European particle-physics laboratory near Geneva, described the production of about 50,000 antihydrogen atoms - the first time such a large quantity has been generated (M. Amoretti et al. Nature 419, 456-459; 2002). And Fermilab, near Chicago, Illinois, is producing upwards of $10^{14}$ antiprotons a year. Howe says it should soon be possible to make the 30 milligrams or so of antimatter needed to send a spacecraft to the Kuiper belt, the band of rocks and ice beyond Neptune.

Howe's design fires an antihydrogen beam at the uranium-coated inner surface of a sail to trigger a fission reaction. He hopes to secure phase II funding, which can provide up to $\$ 500,000$ over two years, to investigate how much momentum this reaction would transfer to the sail, and to study the antimatter storage techniques being developed at CERN and other labs.

Other NIAC fellows want to exploit existing technology. Anthony Colozza at the Ohio Aerospace Institute in Cleveland has his eyes on the 'entomopter', a flying robotic vehicle that mimics the motion of an insect's wings. 

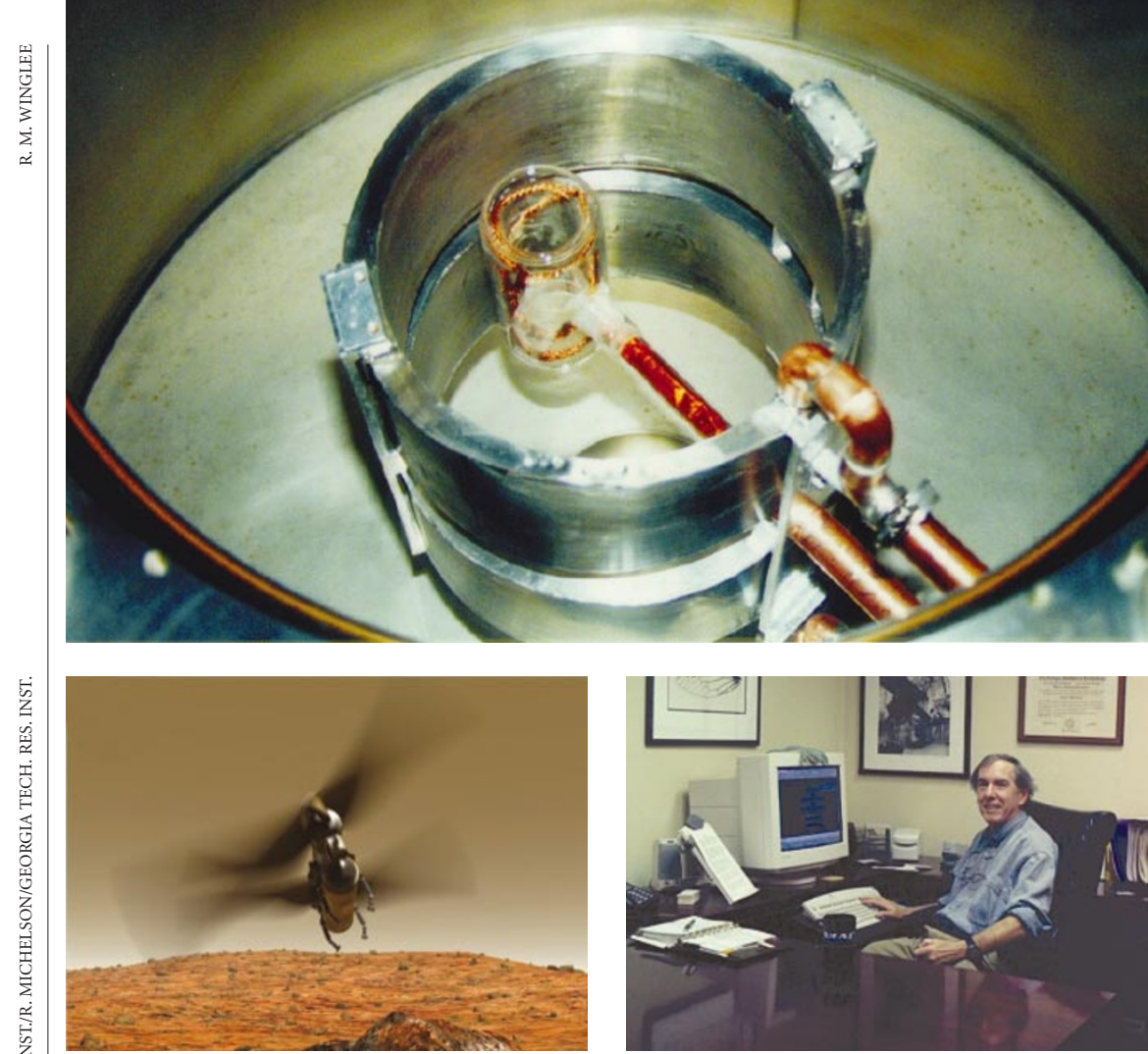

Thrusting forwards: the test set-up for a plasma-induced magnetic bubble (top), and the insect-like Mars entomopter - two of the concepts being backed by Robert Cassanova and his institute.

The device is the work of Robert Michelson, an engineer at the Georgia Tech Research Institute, who developed it for the US Department of Defense. Colozza has designed a system for surveying the surface of Mars using a camera carried by the entomopter. The device is ideal for use on the red planet, where the thin air would make it impossible for craft with conventional wings to fly at low speeds, or to land. NIAC liked the idea enough to give it phase II funding.

Then there are the genuinely novel ideas. In the first round of NIAC grants in 1998, Robert Winglee, a space physicist at the University of Washington in Seattle, won funding for his Mini-Magnetospheric Plasma Propulsion $\left(\mathrm{M}^{2} \mathrm{P}^{2}\right)$ concept. Winglee proposes creating a large magnetic bubble around a spacecraft by using a plasma to expand an existing magnetic field. The bubble would deflect the stream of charged particles, known as the solar wind, that flows from the Sun.

The small but constant pressure against the bubble's large surface area would accelerate a 200-kilogram payload to 80 kilometres per second within three months. A trip to Pluto would take six years, instead of the ten it takes now. Better yet, building such a vehicle would not require huge technological leaps.

The $\mathrm{M}^{2} \mathrm{P}^{2}$ study was an eye-opener for NASA, admits Murray Hirschbein, who is senior adviser to the agency's chief technologist. "Instead of something 10 to 40 years in the future, it may be a lot closer," he says.
Winglee's NIAC grant expired last year, but the work has already produced promising results in test chambers. It is likely to be picked up by NASA's advanced propulsion programme, and the agency might produce a working prototype for testing in space.

\section{Mission improbable}

Not all NIAC fellows are so lucky. The institute aims to draw clever ideas from outside NASA, validate the best ones and have the space agency take over. But some researchers say that "not invented here" attitudes within NASA ensure that few NIAC ideas will ever do more than gather dust.

One such critic is Ivan Bekey, a space technology consultant from Annandale, Virginia, and former head of NASA's advanced concepts programme, an in-house scheme that pre-dates NIAC. After leaving the agency in 1997, he won a phase INIAC grant to study the feasibility of a large space telescope with no supporting structure, just a thin membrane shaped into a reflecting surface. The telescope's instruments would fly in formation to collect radiation reflected by the membrane. If the technique worked, it would lead to revolutionary devices 125 times lighter than the Hubble Space Telescope, but with mirrors ten times the diameter of Hubble's.

Bekey was turned down for a phase II grant but received funding from the National Reconnaissance Office, a government body that builds spy satellites. He says that an advanced concepts programme would be better off run from NASA's Washington headquarters. Bekey doesn't dispute the quality of NIAC's work, but says that it is divorced from the rest of NASA. Without advocates within the agency, NIAC is doomed to generate "nice reports, and that's it", he says.

Success stories such as Winglee's plasma propulsion do indeed appear rare, and most phase II concepts end up as orphans. The entomopter, for example, is too immature a technology to be incorporated into the Mars missions planned for the next decade, which leaves Colozza struggling to find funding to continue his work now that his phase II funding has ended.

But Hirschbein isn't worried if most NIAC ideas languish on the shelf. "These are advanced concepts," he says. "They're not going to find a direct home right away." NIAC's real purpose, he adds, is to influence NASA's "general thought process". That means the NIAC fellows may not even be involved if their idea eventually flies.

But what of NIAC ideas that only a tiny minority believe will ever take off? Projects that are, in Cassanova's words, "on the fringe". Exhibit A is the BlackLight Rocket. According to its backers, the device uses a mysterious new form of power generated when a hydrogen atom becomes a hydrinoa hydrogen atom whose electron is unusually close to its nucleus.

Mainstream physicists contend that electrons cannot approach the nucleus as closely as the hydrino team predicts. But Anthony Marchese, a mechanical engineer at Rowan University in Glassboro, New Jersey, has a phase I grant to study the propulsion possibilities of such an energy source. Marchese doesn't buy all the claims being made by BlackLight Power, the New Jersey company that is developing hydrino-based technologies, but he does believe that "there is something going on that's interesting".

This vagueness, together with the ridicule heaped on hydrino research by figures such as Robert Park, the American Physical Society's director of public information and a keen observer of pseudo-science, makes some NIAC officials nervous about having funded Marchese's work.

But others say this twilight zone between safe and wacky is where NIAC belongs. During a break in the workshop, engineer Donna Shirley, who worked on NASA's celebrated Mars Pathfinder mission in the 1990s before moving to the University of Oklahoma, points out that many of the ideas could be duds, but the investment is worthwhile if an occasional jewel is produced. And the ideas presented at this meeting, says Shirley, are more interesting than the fare at other advanced concepts workshops. But, she adds with a smile, "not as good as at a science fiction convention".

Tony Reichhardt writes for Nature from Washington.

www.niac.usra.edu 